\title{
Confidence, cognitive and somatic anxiety among elite and non-elite futsal players and its relationship with situational factors
}

\author{
Hassan Habibi ${ }^{1}$, Amir Moghaddam², Hossein Soltani ${ }^{3}$ \\ ${ }^{1,2}$ Department of Physical Education and Sport Sciences, Mashhad Branch, Islamic Azad University, Mashhad, Iran. \\ ${ }^{3}$ Department of Physical Education and Sport Sciences, Torbat-e Heydarieh Branch, Islamic Azad University, \\ Torbat-e Heydarieh, Iran.
}

\begin{abstract}
Purpose: $\quad$ The aim of this study was to compare confidence, cognitive and somatic anxiety among elite and non-elite futsal players and its relationship with situational factors.

Material: $\quad 130$ non-elite and 70 elite male futsal players participated in the study. Competitive State Anxiety Inventory-2 and situational factors Inventory were applied. Data was analyzed using one way ANOVA and product moment correlation.

Results: $\quad$ Results showed there was significant difference between competitive state anxiety subscales (cognitive anxiety somatic anxiety \& self-confidence) and situational factors among elite and non-elite futsal players but there was no significant correlations between situational factors subscales among elite and non-elite futsal players.

Conclusions: Competitive state anxiety is part of sport competition and it seems elite athletes can manage and interpret anxiety well with respect to their experiences and psychological intervention and then consider anxiety and situational variables as facilitative factors for his or her competition.

Keywords: competitive state, anxiety, situational factors, elite players.
\end{abstract}

\section{Introduction}

Nowadays, due to lack of attention to sport psychology, athletes may face several failures which bring irreparable damages to them and the sport community. Therefore, paying attention to psychology and the variables related to athletes' performance can have beneficial results. There are important components in psychology that are related to sport performance, one of which is state anxiety [9]. There are so many factors that can cause an athlete to experience stress or anxiety. The elements which can raise stress and anxiety are: physical needs, psychological needs, environmental needs, expectations and pressure to perform to a high level, significant other stressors, relationship issues and life direction concerns [14]. Woodman and Hardy (2001) stated that anxiety is generally known as being an unpleasant emotion [18]. In addition, anxiety is seen as an emotion characterized by negative affect that can have a debilitating effect on performance [5]. Early investigations viewed anxiety as onedimensional, whereas more recent research has suggested that anxiety is multidimensional [6]. Comprising of both: mental component and physiological component. The mental part of anxiety has been referred cognitive anxiety and the physiological part termed physiological arousal or somatic anxiety. Morris, Davis and Hutchings (1981) defined cognitive anxiety as "the cognitive components of anxiety, such as fear of result and cognitive concerns about oneself and competition and somatic anxiety as "one's perception of the physiological-affective elements of the anxiety experience, that is, indications of autonomic arousal and unpleasant feeling states such as nervousness and tension [12]. In the last century, scholars have paid great attention to the relationship between anxiety and sport performance [7]. In competitive sports, (C) Hassan Habibi, Amir Moghaddam, Hossein Soltani, 2017 doi:10.15561/18189172.2017.0202 anxiety and self-confidence are considered two essential factors affecting the athlete's performance [11]. The effects of anxiety and self-confidence levels on sport performance are a major concern of athletes and coaches involving in different sports. Successful coaches often know that in competitive sports, the competitors' level of skill is similar to each other and the difference is in their mental readiness [3]. It is for this reason that they prepare the athletes for effective confrontation with high levels of anxiety and stress. If they are not ready, they may be weakened and surrendered by the pressures of the competition. As a factor related to mental energy, anxiety has been always taken into account in athletes' mental health. It is clear that when an athlete faces a special condition such as that of a competition and is observed by spectators, in the first stage he compares what is expected from him with his own level of skill. If he is concerned with requirements and expectations, he will definitely experience the stress resulting from his anxiety. The point is that even if he feels that his abilities and skills are higher than the requirements of a competition, he will still have stress because stress originates from incompatibility and asymmetry between wishes and qualifications. So it is clear that tranquility and relief are obtained through concordance and compatibility between these two factors. On the other hand, being away from the surrounding events may result in stress because this is also considered a kind of mental pressure [2]. The important mental challenge of the athlete may be his lack of understanding the difference between the two concepts of mental energy and stress. This challenge will overcome both the athlete and his coach because their main problem is to find the optimum and desirable level of these two factors. One of the inherent aspects of sport competitions is the players' need to meet the requirements of the competition and show 
satisfactory performance under the competition pressures. Feeling an essential inconsistency between environmental needs and reactivity or responsiveness capabilities under the conditions in which failure in meeting the competition expectations brings significant consequences, increases competitive state anxiety. Some of the scholars concluded that situational factors have an important role in adjusting athletes' competitive state anxiety before the competition. In order to have desirable performance in sport races, it is necessary to identify factors that affect anxiety. Some scholars whether inside or outside of the country have studied anxiety of different skill players and its relationship with situational factors. Additionally, studies conducted on anxiety levels in different sports have had contradictory results [2]. Martens (1990) proposed this hypothesis that the origin of anxiety and self-confidence is environmental factors which are related to athlete's expectations from the status of the competition and primarily include the understanding of one's own abilities based on previous competitive experiences and of competitor's ability and strength. As a result, when expectations are irrational, the athlete will experience increase in his anxiety and decrease in his self-confidence. Signs that cause physical anxiety mainly include conditional responses to stimuli in a sport environment, such as changing the lockers, common warm-ups before the competition, significance of the game, and populace of spectators [10]. Smith (1990) states that situational factors include the significance of the sport race, competitor's ability and strength, presence of VIPs, and the degree to which social support is perceived by the coach, teammates, parents and fans [15]. In this study, situational factors refer to performance expectations from the team, performance expectations from the individuals, competitor's ability and strength, the importance of the result for the team, previous performances, mental readiness of the individuals, and physical readiness of the individuals. Therefore, since futsal has gained special value and popularity as one of the attractive and hot sports in the world and in Iran, and children, teenagers, the youth and even adults are extensively attracted by it, it is necessary to study the psychological factors affecting the behavior of athletes of this sport based on the results of the conducted studies, the significance of anxiety and its role in athletes' performance, and lack of required research in this field. Hence, by investigating the comparison of competitive state anxiety of young elite and non-elite futsal players according to situational factors, the author attempts to help athletes interested in this sport to reach the elite level.

\section{Material and Methods}

The research methodology used in this study was descriptive comparative and correlation.

\section{Participants}

The statistical population used in this research was 560 futsal players (160 elite futsal player \& 400 non-elite futsal player) in Iran. By using Morgan table 130 nonelite futsal and 70 elite futsal, players were considered as sample size randomly. Samples were male futsal players who had competed in the league and super league competitions of Iran (Khorasan Razvi State) in 2014 year. In this research skill level (elite \& nonelite) and situational factors (performance expectations team, performance expectations individuals, opponent's ability, the importance of the result for the team, previous performances, mental readiness and physical readiness of the individuals have been considered as independent variables and competitive state anxiety subscales (somatic anxiety, cognitive anxiety and self-confidence) were dependent variables'.

\section{Measures}

Situational factors Inventory (Swain, 1990).

This inventory contains 8 questions utilizing a 9-point Likert scales from 1 (low) to 9 (high) regarding performance expectations of the team, performance expectations of the individuals, opponent's ability and strength, the importance of the result for the team, previous performances, mental readiness and physical readiness of the individuals.

Competitive State Anxiety Inventory-2 (Martens, Vealey and Burton, 1990)

This measurement tool is often used in research studies in order to estimate the participants' cognitive and somatic types of anxieties, as well as their self-confidence (Martens et al., 1990). The test requires the subjects to choose the answer that corresponds with how they feel at this point in time, right now. Cognitive anxiety items are numbers $1,4,7,10,13,16,19,22$, and 25 . Somatic anxiety items are numbers 2, 5, 8, 11, 14 (reverse), 17, 20, 23 , and 26. Self-confidence items are numbers 3, 6, 9, 12, $15,18,21,24$, and 27.

According to Martens et al. (1990) the scoring of the CSAI-2 was achieved in the following way. Persons rated how they were feeling right at that moment by circling one of the presented answers. The four-presented answers included: not at all (1), somewhat (2), moderately so (3) and very much so (4). The final scores for each subscale ranged from 9 to 36, with 9 indicating low anxiety/ confidence and 36 indicating high anxiety/confidence. The reliability was measured by Alpha Cronbach $("=0.89)$. Also, internal reliability of this questionnaire was reported by Peter et al. (2003) as 85.75 , and 0.83 respectively.

\section{Procedures}

At first, the researcher visited coaches from the various teams that had been selected as sample and explained the nature of the study. In the second stage the researcher $\mathrm{d}$ distributed materials containing a letter describing the study and informed-consent forms. At the third stage Personal Information Questionnaire, state Competitive Anxiety Inventory (CSAI-2) and Situational factors Inventory for both elite and non-elite futsal players were administered to the subjects within 30 minutes prior to the start of the competition and the nature of study was described at the top of the questionnaire to the subjects. Each questionnaire took approximately 5 minutes to complete.

\section{Statistical Analysis}

In order to calculate measures of central tendency 
and variability, descriptive statistics was utilized. At first Levene's test checked homogeneity of variances between sets of scores. Homogeneity of variance for participant samples was observed. Finally One way analysis of variance was conducted for between group's comparisons, then the hypotheses were examined at $\mathrm{P}<0.05$.

\section{Results}

Table1 shows that there is significant difference between competitive state anxiety subscales (cognitive anxiety somatic anxiety \& self-confidence) and situational factors among elite and non-elite futsal players $(\mathrm{P}<0.05)$. Table 2 showed there is no significant correlations between situational factors subscales factors among elite and non-elite futsal players $(\mathrm{P}<0.05)$.

\section{Discussion}

Results of one-way analysis of variance concerning the first and second purposes of this research showed that elite futsal players experienced lower levels of physical and cognitive anxiety than non-elite players. Statistically, there was a significant difference between the levels of cognitive anxiety and physical anxiety of elite and nonelite futsal players. Findings of this study regarding these three variables highlight the multidimensional theory of state anxiety [12] and confirm this theory because there was a negative linear relationship between the levels of cognitive anxiety of elite and non-elite players. In fact, the higher the level of cognitive anxiety, the weaker the performance will be. On the other hand, according to this theory, the relationship between physical anxiety and performance is like an upside-down U. Results of this research showed that elite players experienced higher levels of physical anxiety compared to cognitive anxiety. This indicates that all players in all levels should experience an optimum level of anxiety so that they can have better performance. In fact, physical anxiety affects performance less than the cognitive anxiety. There are different theories about anxiety and sport performance; and regardless of the acceptance or rejection of a theory, anxiety definitely affects athletes' performance in different forms. In this research, both elite and non-elite futsal players experienced anxiety. Of course, considering the athletes' personality traits, average levels of anxiety seem to be necessary, and the difference between elite and non-elite athletes is in their controlling and managing of stressors, in a way that it seems that this group of athletes considers stress and anxiety produced before the competition as a facilitating factor in performing the sport competitions. In contrast, non-elite athletes consider stressors as a prohibitive factor. In addition, since elite players have more experience than non-elite athletes and

Table 1. Comparison of competitive state anxiety subscales and situational factor among elite and non-elite futsal players

\begin{tabular}{|c|c|c|c|c|c|c|}
\hline Variable & Skill level & $\mathbf{N}$ & M & SD & $\mathbf{F}$ & Sig. \\
\hline \multirow{2}{*}{ Cognitive Anxiety } & Elite players & 70 & 14.74 & 2.86 & \multirow{2}{*}{5.36} & \multirow{2}{*}{$0.000^{*}$} \\
\hline & Non-elite players & 130 & 18.30 & 3.63 & & \\
\hline \multirow{2}{*}{ Somatic Anxiety } & Elite players & 70 & 15.94 & 2.72 & \multirow{2}{*}{16.91} & \multirow{2}{*}{$0.000^{*}$} \\
\hline & Non-elite players & 130 & 17.91 & 3.47 & & \\
\hline \multirow{2}{*}{ Self-confidence } & Elite players & 70 & 17.90 & 2.40 & \multirow{2}{*}{49.12} & \multirow{2}{*}{$0.000^{*}$} \\
\hline & Non-elite players & 130 & 15.33 & 2.49 & & \\
\hline \multirow{2}{*}{ Situational Factors } & Elite players & 70 & 52.98 & 5.91 & \multirow{2}{*}{152.12} & \multirow{2}{*}{$0.000^{*}$} \\
\hline & Non-elite players & 130 & 40.70 & 7.69 & & \\
\hline
\end{tabular}

Table 2. Correlation of competitive state anxiety subscales and situational factor among elite and non-elite futsal players

\begin{tabular}{|c|c|c|c|c|}
\hline Variables & Skill level & $\mathbf{N}$ & $r$ & Sig. \\
\hline $\begin{array}{l}\text { Situational Factors } \\
\text { Cognitive Anxiety }\end{array}$ & Elite Players & 70 & 0.053 & 0.665 \\
\hline $\begin{array}{l}\text { Situational Factors } \\
\text { Somatic Anxiety }\end{array}$ & Elite Players & 70 & 0.022 & 0.854 \\
\hline $\begin{array}{l}\text { Situational Factors } \\
\text { Self-confidence }\end{array}$ & Elite Players & 70 & 0.068 & 0.576 \\
\hline $\begin{array}{l}\text { Situational Factors } \\
\text { Cognitive Anxiety }\end{array}$ & Non-elite Players & 130 & 0.017 & 0.844 \\
\hline $\begin{array}{l}\text { Situational Factors } \\
\text { Somatic Anxiety }\end{array}$ & Non-elite Players & 130 & 0.057 & 0.520 \\
\hline $\begin{array}{l}\text { Situational Factors } \\
\text { Self-confidence }\end{array}$ & Non-elite Players & 130 & 0.095 & 0.284 \\
\hline
\end{tabular}


have participated in more races in their life time, it is obvious that they can deal with the produced stress and anxiety more easily. Also, these athletes have been more trained by experienced and expert coaches. Considering that training mental skills and strategies of overcoming stress is part of the elite players' practices, it seems that these players experience lower levels of anxiety. The results of this hypothesis (significance of the levels of cognitive and physical anxiety among elite and non-elite players) conform to the results of studies conducted by Soltani, 2003; Anshel et al., 2001 \& Jones et al., 1994). Jones reported that elite players consider anxiety as a facilitating factor in performance, while non-elite athletes are affected by adverse effects of anxiety.

The third purpose of this research was to compare the self-confidence of elite and non-elite futsal players. The results of one-way analysis of variance showed that elite futsal players had higher average self-confidence compared to non-elite futsal players. In other words, there is a significant difference between average self-confidence of elite and non-elite futsal players $(\mathrm{P}<0.05)$.

It seems that relatively high levels of self-confidence in elite players is attributed to high levels of experience, mental skills, more success in competitive races and playing logical mental games. It seems that elite athletes develop and maintain their self-confidence through mental readiness practices. In addition, when running races, they do not allow intervening, negative and unrelated thoughts to influence their self-confidence. Elite athletes view mistakes in competitive games as part of the human's mistakes. Additionally, exposing athletes to the programs of intellectual and mental practices from childhood makes this possibility that it exerts positive effects on their self-confidence level and this can be transferred to sport experiences in adulthood [13]. The results of this hypothesis conform to the results of studies conducted by Soltani (2013), Esfahani (2010) and Bahram (2004).

The fourth purpose of this research is to compare situational factors of elite and non-elite futsal players, in which the one-way analysis of variance showed that there is a significant difference between the average score of situational factors of elite and non-elite players. Since elite players have been more exposed to psychological training and mental skills practicing for the sake of achieving high levels of competition, it seems that they are more compatible with situational factors and environmental conditions of the competition including performance requirements of individuals and the team, competitor's ability and strength, significance of the results for the team, previous performances, importance of the event, etc. In other words, they are well aware of the strategies of confronting critical conditions and stressors. They also do not allow anything that negatively affects their selfconfidence in competitive situations. The results of the first, second and third hypotheses of this research confirm this assumption. Moreover, exposing athletes to the programs of intellectual and mental practices from childhood makes this possibility that it exerts positive effects on their self-confidence level and this can be transferred to sport experiences in adulthood [13]. Conducting more studies about the purpose of this research seems to be necessary because of the inadequate literature review.

The fifth, sixth and seventh purposes of the present research were to determine the relationship between competitive state anxiety (cognitive anxiety, somatic anxiety and self-confidence) and situational factors in elite futsal players. Pearson's correlation coefficient showed that there is no significant correlation between cognitive anxiety, physical anxiety and self-confidence of elite players and situational factors.

Considering the negative, weak relationship between the intended situational factors of this study and physical and cognitive anxiety, it seems that even the high average scores and positive situational factors do not lead to increase or decrease of anxiety levels, or they do not have any cause and effect relationship with anxiety reduction. It seems that changes in cognitive and physical anxiety levels are more related to personality traits, individual differences and or trait anxiety levels. Since there is little literature regarding the results of these hypotheses outside of our country and there is no literature about this topic inside our country, conducting more studies on this subject seems to be necessary.

The eighth, ninth and tenth purposes of the present research were to determine the relationship between competitive state anxiety (cognitive anxiety, physical anxiety and self-confidence) and situational factors in non-elite futsal players. Pearson's correlation coefficient showed that there is no significant correlation between cognitive anxiety, physical anxiety and self-confidence of non-elite players and situational factors. Although the researcher predicted that there should be a strong relationship between high levels of anxiety in non-elite futsal players and situational factors - because non-elite athletes do not have enough and the required experience in many of the sport events, are not matured mentally, are excessively excited and anxious when facing environmental conditions of the competition, and consider anxiety as a prohibitive factor the researcher found a very weak relationship between competitive state anxiety and situational factors. This assumption is reinforced that each individual's personality essence and trait anxiety, play a decisive role in anxiety levels.

\section{Conclusion:}

Although competitive state anxiety is part of sport competition, the levels of state anxiety subscales in elite and non-elite athletes was different in the present study. Elite athletes experienced lower levels of cognitive anxiety and average levels of somatic anxiety compared with non-elite players. It seems elite athletes can manage and interpret anxiety well with respect to their experiences and more physical and psychological intervention so consider anxiety and situational variables as facilitative factors for their competition.

\section{Conflict of interests}

The authors declare that there is no conflict of interests. 


\section{References}

1. Anshel HM, Kim KW, Kim BH, Chang KJ, \& Eom HJ. A model for coping with stressful events in sports; Theory, application and future directions. International Journal of Sport Psychology, 2001;32(1): 43-75.

2. Anshel Mark H. Sport Psychology: From Theory to Practice (5th Edition), Benjamin Cummings; 2011.

3. Bridges Ashley, Knight Brandon. Somatic anxiety in athletic performance. Hanover college independent study; 2005.

4. Esfahani N, H Gheze Soflu. The Comparison of PreCompetition Anxiety and State Anger between Female and Male Volleyball Players. World Journal of Sport Sciences, 2010; 3(4): 237-242.

5. Eysenck MW. A handbook of cognitive psychology. London: Erlbaum; 1984

6. Fazey JA, Hardy L. The inverted U hypothesis: A catastrophe for sport psychology. Leeds, UK: British Association of Sports Sciences Monograph,The National Coaching Foundation; 1988.

7. Gold D, Horn T, Spree Man J. Sources of stress in junior elite. Wrestlers, journal of sport psychology. 2000;1:23-29.

8. Jones G, Hanton S, Swain A. Intensity and Interpretation of Anxiety Symptoms in Elite and Non-elite Sport Performers. Personal and Individual Differences, 1994; (17): 657-663.

9. Keyvan A. Comparison of trait anxiety among selected athletes in national athletic competition, Ofis conference; 2010.
10.Martens R, Burton D. Competitive anxiety in sport. USA: Human Kinetics publisher; 1990.

11. Martens R, Burton D, Vealey RS, Bump LA, Smith DE. Development and validation of the sport stress. 1990.

12.Morris LW, Harris EW, Rovins DS. Interactive effects of generalized and situational expectancies on cognitive and :emotional components of social anxiety. Journal of Research in Personality. 1981; 15, 302-311.

13.Momoci T, Donzelli G, Johnson J. Personality differences and Achievement level is Sport. Journal of sport psychology. 2004;1:34-40.

14.Thomas Reilly, A Mark Williams. Science and soccer, second edition, Routledge; 2003.

15.Smith RE, Smoll FL, Ptacek JT. Conjunctive moderator variables in vulnerability and resiliency research: Life stress, social support and coping skills adolescent sport injuries. Journal of Personality and Social Psychology. 1990; 58: 360-370.

16.Soltani H. Comparative Analysis of Competitive State Anxiety among Elite and Non -Elite karate Athletes in Iran, Advances in Environmental Biology, 2003;7 (7):1244-1248.

17.Swain ABJ. Competitive State Anxiety: Towards A Clearer Understanding. A Doctoral Thesis Submitted in Partial Fulfillment of the Requirements for the Award of Doctor of Philosophy of the Loughborough University of Technology; 1990.

18.Woodman T, Hardy L. Stress and anxiety. New York: John Wiley \& Sons, Inc.; 2001.

\section{Information about the authors:}

Hassan Habibi; http://orcid.org/0000-0002-5827-398X; hsn_habibi55@yahoo.com; Department of Physical Education and Sport Sciences, Mashhad Branch, Islamic Azad University; Mashhad, Iran.

Amir Moghaddam; http://orcid.org/0000-0002-6324-2758; moghaddam.a@mshdiau.ac.ir; Department of Physical Education and Sport Sciences, Mashhad Branch, Islamic Azad University; Mashhad, Iran.

Hossein Soltani; http://orcid.org/0000-0003-3985-2385; soltani hn@yahoo.com; Department of Physical Education and Sport Sciences, Torbat-e Heydarieh Branch, Islamic Azad University; Torbat-e Heydarieh, Iran.

Cite this article as: Hassan Habibi, Amir Moghaddam, Hossein Soltani. Confidence, cognitive and somatic anxiety among elite and non-elite futsal players and its relationship with situational factors. Pedagogics, psychology, medical-biological problems of physical training and sports, 2017;2:60-64. doi:10.15561/18189172.2017.0202

The electronic version of this article is the complete one and can be found online at: http://www.sportpedagogy.org.ua/index.php/PPS/issue/archive

This is an Open Access article distributed under the terms of the Creative Commons Attribution License, which permits unrestricted use, distribution, and reproduction in any medium, provided the original work is properly cited (http://creativecommons.org/licenses/by/4.0/deed.en).

Received: 29.12 .2016

Accepted: 15.01.2017; Published: 30.04 .2017 